\title{
УДОБРЕНИЕ САФЛОРА НА ТЕМНО-КАШТАНОВОЙ ПОЧВЕ В СЕВЕРО-ВОСТОЧНОЙ ЗОНЕ РОСТОВСКОЙ ОБЛАСТИ
}

Сафлор - это масличное растение, возделывается в засушливых зонах. Так же как и подсолнечник, сафлор относится к семейству сложноцветных [Андриюк А.В, 2014].

Плод сафлора - семянка с твердой, трудно раскрывающейся оболочкой. Масло сафлора близко к подсолнечному, но более насыщена линолевой $(77 \%)$ и олеиновой $(15,0 \%)$ кислотами [Темирбекова С.Н., 2015].

На сегодняшний день в России 56 млн га пашни (45\%) характеризуются низким содержанием гумуса, 28 млн га (23\%) - недостатком фосфора и 11,5 млн га (9\%) - калия. Среднегодовой дефицит гумуса в пахотном слое в последние годы в среднем по стране составляет 0,52 т/га, а по отдельным регионам - от 0,25 до 0,72 т/га [Чекмарёв П.А., Лукин С.В., 2013]. Сафлор является отличным сидеральным удобрением. Согласно расчетов, Д.А. Постникова, С.К. Темирбекова (2014), после заделки надземной массы сафлора в почву поступает 189 кг/га азота и 45 кг/га фосфора.

Сафлор не требователен к качественным показателям почвы. Он может расти в малоплодородном грунте и даже в засоленном. Но наибольшую урожайность сафлор демонстрирует на черноземе и каштановых почвах. Отлично подходят для посадки суглинистые и супесчаные почвы. Высокий уровень грунтовых вод также является предпочтительным фактором для выращивания сафлора. Но даже в засушливых районах и неблагоприятных условиях это растение показывает высокую урожайность, в отличие от других масленичных культур [Ружейникова Н.М., Кулева Н.Н., Зайцев А.Н. 2012].

В отличии от подсолнечника сафлор убирается рано, после уборки сафлора в $0-100$ см слое почвы остается на $106-118$ м³/га воды, 16 -19 кг азота, 25 - 29 кг фосфора и 18 - 24 кг/га калия больше, чем после подсолнечника [Конопля Н., 2013].

В Ростовской области на данный момент нет опытов по применению минеральных удобрений и бактериальных препаратов под сафлор, но в книге 
«Зональные системы земледелия Ростовской области на 2013-2020 годы» упоминается о минеральных удобрениях под основную обработку почвы под сафлор, при посеве и междурядную культивацию [Бондаренко С.Г., Горбаченко Ф.И., Горячев В.П., 2013].

Полевые опыты проводились в 2016-2018 гг., на полях СПК «Заря» Обливского района Ростовской области на тёмно - каштановых почвах. Климат зоны проведения исследований засушливый, умеренно континентальный [Хрусталев Ю.П., Василенко В.Н., 2002]. Объект исследования - сорт сафлора Заволжский-1. Повторность опыта трехкратная. Площадь делянки - $130 \mathrm{~m}^{2}$ (7,2м×18м), учетная $-108 \mathrm{~m}^{2}$. Агротехника - общепринятая для зоны.

Сафлор во все годы исследования высевали после озимой пшеницы. Закладка опытов, проведение наблюдений и учётов в течение вегетации осуществляли согласно методикам опытов с удобрениями.

Схема опыта представлена в таблице 1. Применяли бактериальные препараты, изготовленные во Всероссийском институте сельскохозяйственной микробиологии (ВНИИСХМ), г. Санкт-Петербург, со штаммами ассоциативных азотфиксаторов: Мизорин, Флавобактерин, КЛ-10 и минеральные удобрения аммиачная селитра $(34,6 \% \mathrm{~N})$, аммофос $(12 \% \mathrm{~N}$ $\left.50 \% \quad \mathrm{P}_{2} \mathrm{O}_{5}\right)$ и хлористый калий $\left(60 \% \mathrm{~K}_{2} \mathrm{O}\right)$. Перед посевом сафлора удобрения вносились вручную с последующей заделкой культиватором и при посеве сеялкой С3-3,6. Бактериальные препараты вносились одновременно с посевом путём инокуляции семян с расчета 300 г/га. Уборку урожая сафлора проводили поделяночно вручную с пересчетом урожайности на стандартную влажность.

В ходе исследований установлено, что запас продуктивной влаги в метровом слое почвы перед посевом сафлора во все годы исследования была не высокая, в 2016 году составила 83,2 мм, в 2017 году - 130,6 мм, а в 2018 году - 125,4 мм, что свидетельствует о неодинаковом количестве выпавших осадков за осенне-зимний и весенний период. В ходе развития растений во все годы исследования наблюдалось резкое снижение содержания продуктивной влаги вплоть до фазы цветения. В период цветение-полная спелость доступная влага в метровой толще почвы вовсе стала нулевой. 
Перед посевом сафлора на исследуемых участках суммарное содержание азота в 2016 году 30 кг/га, в 2017 году 39,5 кг/га, а в 2018 году 24,5 кг/га. Обеспеченность почвы подвижными формами фосфора и калия составляет - в 2016 году 16,8 и 421 мг/кг, в 2017 году 8,4 и 360 мг/кг, в 2018 году 19,3 и 221 мг/кг соответственно по градации Мачигина.

Условия увлажнения в годы закладки опытов повлияли на уровень урожайности сафлора, как на контроле, так и в вариантах с удобрениями. В 2016 году на контроле урожайность составила 0,92 т/га (табл.1). Оценивая действие минерального удобрения, применяемого под предпосевную культивацию, наибольшая прибавка была получена на варианте с дозой $\mathrm{N}_{48} \mathrm{P}_{52}$. Прибавка составила 0,26 т/га или 28,3\%. Максимальная урожайность наблюдалась на варианте с ассоциативными штаммами бактерий на фоне естественного плодородия почвы на варианте с Флавобактерином (1,12 т/га). Что касается совместного применения минеральных удобрений и бактериальных препаратов, то они значительно уступали действию от Мизорина в чистом виде.

В 2017 г. на контроле урожайность составила 1,11 т/га. Вариант с дозой минеральных удобрений, применяемых под предпосевную культивацию в дозе $\mathrm{N}_{48} \mathrm{P}_{52} \mathrm{~K}_{48}$ обеспечило прибавку по сравнению с контролем на 0,26 т/га или на 23,7\%. Максимальный эффект от применения бактериальных препаратов без удобрений в этот год исследований уступал $\mathrm{N}_{24} \mathrm{P}_{52}+\mathrm{KЛ}-10$. Прибавка на этом варианте составила 0,16 т/га или 14,1\%.

Таблийа 1

Урожайность сафлора в 2016-2018 гг., т/га

\begin{tabular}{|c|c|c|c|c|c|c|c|c|c|c|c|c|}
\hline \multirow[t]{2}{*}{ Варианты } & \multirow[t]{2}{*}{$\frac{\dot{b}}{\stackrel{0}{0}}$} & \multicolumn{2}{|c|}{$\begin{array}{c}\text { Прибавка к } \\
\text { контролю }\end{array}$} & \multirow[t]{2}{*}{$\stackrel{\stackrel{亡}{2}}{\stackrel{2}{2}}$} & \multicolumn{2}{|c|}{$\begin{array}{c}\text { Прибавка к } \\
\text { контролю }\end{array}$} & \multirow[t]{2}{*}{$\stackrel{\dot{L}}{\infty}$} & \multicolumn{2}{|c|}{$\begin{array}{c}\text { Прибавка к } \\
\text { контролю }\end{array}$} & \multirow[t]{2}{*}{$\begin{array}{c}\text { Сред } \\
\text { няя за } \\
3 \\
\text { Года }\end{array}$} & \multicolumn{2}{|c|}{$\begin{array}{c}\text { Прибавка } \\
\text { к } \\
\text { контролю, } \\
\text { за } 2016 \text { - } \\
2018 \text { гг. }\end{array}$} \\
\hline & & т/га & $\%$ & & т/га & $\%$ & & т/га & $\%$ & & т/га & $\%$ \\
\hline Контроль & 0,92 & - & - & 1,11 & - & - & 0,94 & - & - & 1,03 & - & - \\
\hline \multicolumn{13}{|c|}{ внесение при посеве } \\
\hline $\mathrm{N}_{24} \mathrm{P}_{26}$ & 1,01 & 0,09 & 9,8 & 1,23 & 0,12 & 10,8 & 1,05 & 0,11 & 11,7 & 1,09 & 0,06 & 5,8 \\
\hline $\mathrm{N}_{24} \mathrm{P}_{26} \mathrm{~K}_{24}$ & 1,01 & 0,09 & 9,8 & 1,22 & 0,11 & 9,9 & 1,06 & 0,12 & 12,8 & 1,09 & 0,06 & 5,8 \\
\hline $\mathrm{N}_{24} \mathrm{P}_{52}$ & 1,01 & 0,09 & 9,8 & 1,25 & 0,14 & 12,6 & 1,04 & 0,1 & 10,6 & 1,10 & 0,07 & 6,8 \\
\hline $\mathrm{N}_{48} \mathrm{P}_{52}$ & 0,96 & 0,04 & 4,3 & 1,21 & 0,1 & 8,7 & 0,94 & 0 & 0 & 1,04 & 0,01 & 0,9 \\
\hline
\end{tabular}




\begin{tabular}{|l|c|c|c|c|c|c|c|c|c|c|c|c|}
\hline \multicolumn{10}{|c|}{ вразброс под предпосевную культивацию } \\
\hline $\mathrm{N}_{24} \mathrm{P}_{52}$ & 1,09 & 0,07 & 7,6 & 1,29 & 0,18 & 16,5 & 1,09 & 0,15 & 15,9 & 1,16 & 0,13 & 12,6 \\
\hline $\mathrm{N}_{48} \mathrm{P}_{52}$ & 1,18 & 0,26 & 28,3 & 1,31 & 0,2 & 18,3 & 1,18 & 0,24 & 25,5 & 1,22 & 0,19 & 18,4 \\
\hline $\mathrm{N}_{48} \mathrm{P}_{52} \mathrm{~K}_{48}$ & 1,08 & 0,16 & 17,4 & 1,37 & 0,26 & 23,7 & 1,08 & 0,14 & 14,9 & 1,18 & 0,15 & 14,6 \\
\hline $\mathrm{N}_{72} \mathrm{P}_{52}$ & 1,11 & 0,19 & 20,7 & 1,30 & 0,19 & 16,8 & 1,06 & 0,12 & 12,8 & 1,16 & 0,13 & 12,6 \\
\hline $\mathrm{N}_{72} \mathrm{P}_{52} \mathrm{~K}_{48}$ & 1,06 & 0,14 & 15,2 & 1,29 & 0,18 & 16,2 & 1,03 & 0,09 & 9,6 & 1,13 & 0,1 & 9,7 \\
\hline \multicolumn{10}{|c|}{ внесение минеральных удобрений при посеве } \\
\hline КЛ-10 & 0,94 & 0,02 & 2,2 & 1,25 & 0,14 & 12,3 & 0,98 & 0,04 & 4,3 & 1,04 & 0,01 & 0,9 \\
\hline $\begin{array}{l}\mathrm{N}_{24} \mathrm{P}_{52}+\mathrm{K} \\
\text { Л-10 }\end{array}$ & 1,07 & 0,15 & 16,3 & 1,27 & 0,16 & 14,1 & 1,07 & 0,13 & 13,8 & 1,14 & 0,11 & 10,7 \\
\hline Мизорин & 0,95 & 0,03 & 3,3 & 1,20 & 0,09 & 7,8 & 1,01 & 0,07 & 7,4 & 1,05 & 0,02 & 1,9 \\
\hline $\begin{array}{l}\mathrm{N}_{24} \mathrm{P}_{52}+\mathrm{M} \\
\text { изорин }\end{array}$ & 1,02 & 0,2 & 21,7 & 1,14 & 0,03 & 2,7 & 1,0 & 0,06 & 6,4 & 1,07 & 0,04 & 3,9 \\
\hline $\begin{array}{l}\text { Флавобак } \\
\text { терин }\end{array}$ & $\mathbf{1 , 1 2}$ & $\mathbf{0 , 2}$ & $\mathbf{2 1 , 7}$ & 1,25 & 0,14 & 12,6 & $\mathbf{1 , 1 4}$ & $\mathbf{0 , 2}$ & $\mathbf{2 1 , 3}$ & $\mathbf{1 , 1 7}$ & $\mathbf{0 , 1 4}$ & $\mathbf{1 3 , 6}$ \\
\hline $\begin{array}{l}\mathrm{N}_{24} \mathrm{P}_{52}+\Phi \\
\text { лавобакте } \\
\text { рин }\end{array}$ & 1,08 & 0,16 & 17,4 & 1,16 & 0,05 & 4,5 & 1,08 & 0,14 & 14,9 & 1,11 & 0,08 & 7,8 \\
\hline НСР & & 0,05 & & \multicolumn{10}{|c|}{0,10} & & & 0,07 & & & 0,07 & \\
\hline
\end{tabular}

В 2018 году на контроле урожайность составила 0,94 т/га. Увеличение урожайности на варианте с дозой N48P52 по сравнению с контролем составило 0,24 т/га, или 25,5\%. На естественном фоне плодородия применение ассоциативных азотфиксаторов положительно сказалось на варианте Флавобактерин, с урожайностью сафлора 1,14 т/га. Что касается совместного применения минеральных удобрений и бактериальных препаратов, то они значительно уступали действию от Флавобактерина в чистом виде.

Оценивая действие от минеральных удобрений, применяемых при посеве, то во все годы исследования на всех вариантах с разными дозами не дало положительного эффекта, прибавка в среднем за 3 года составила 0,05 т/га или 4,8\%.

В среднем за 2016-2018 гг. урожайность сафлора на контрольном варианте составила 1,03 т/га. От внесения минеральных удобрений вразброс под предпосевную культивацию в дозе $\mathrm{N}_{48} \mathrm{P}_{52}$ урожайность повысилась на $18,4 \%$. Сушественное повышение урожайности во все годы исследований обеспечила обработка семян бактериальным препаратом Флавобактерин. В среднем за 3 года урожайность по сравнению с контролем была выше на $13,6 \%$. Сочетание применения штаммов азотфиксаторов на фоне азотно- 
фосфорных удобрений было не эффективно. Прибавки урожайности меньше по сравнению с контрольным вариантом, чем от действия штамма Флавобактерин на естественном фоне плодородия.

Содержание масла в семенах сафлора в годы проведения опытов 2016-2018 гг. изменялось незначительно на всех вариантах опыта и составило 35,7-36,3\%. Полученные результаты позволяют сделать вывод, что изучаемые агрохимические приемы не влияли на содержание масла в семенах сафлора.

На контрольном варианте сбор масла с 1 га в среднем за 3 года составил 337 кг. В среднем за три года максимальная прибавка получена при внесении минеральных удобрений вразброс под предпосевную культивацию в дозе N48P52. Увеличение по сравнению с контрольным вариантом составило $23,7 \%$.

Следует отметить очень широкий разброс прибавки сбора масла в урожае семян сафлора на вариантах опыта от 22 до 80 кг/га. Основной причиной могут являться различия в урожайности семян, так как на масличность при внесении минеральных удобрений и бактериальных препаратов существенно не изменялась.

Среди изучаемых бактериальных препаратов штамм Флавобактерин в чистом в виде показал лучший результат во влиянии на сбор масла. Прибавка к контролю составила 51 кг/га или 18,1\%.

1. Рекомендации производству. Для повышения урожайности семян сафлора и увеличения сбора масла в условиях северо-восточной зоны Ростовской области необходимо применять минеральные удобрений вразброс под предпосевную культивацию в дозе N48P52.

2. При посеве сафлора без минеральных удобрений целесообразно использовать бактериальный препарат Флавобактерин из расчета 300 г на гектарную норму.

Таблиия 2

\section{Влияние минеральных удобрений и бактериальных препаратов} на сбор масла, кг/га

\begin{tabular}{|c|c|c|c|c|c|c|}
\hline \multirow{2}{*}{ Варианты } & \multirow{2}{*}{2016 г. } & 2017 г. & 2018 г. & \multirow{2}{*}{$\begin{array}{c}\text { Среднее } \\
\text { за 3 года }\end{array}$} & \multicolumn{2}{|c|}{$\begin{array}{c}\text { Прибавка } \\
\text { к контролю }\end{array}$} \\
\cline { 5 - 7 } & & & & & кг/га & $\%$ \\
\hline контроль & 305 & 368 & 339 & 337 & - & - \\
\hline \multicolumn{3}{c}{ внесение минеральных удобрений при посеве } \\
\hline
\end{tabular}




\begin{tabular}{|l|c|c|c|c|c|c|}
\hline $\mathrm{N}_{24} \mathrm{P}_{26}$ & 335 & 413 & 381 & 376 & 39 & 11,6 \\
\hline $\mathrm{N}_{24} \mathrm{P}_{26} \mathrm{~K}_{24}$ & 337 & 397 & 380 & 371 & 34 & 10,1 \\
\hline $\mathrm{N}_{24} \mathrm{P}_{52}$ & 335 & 415 & 375 & 375 & 38 & 11,3 \\
\hline $\mathrm{N}_{48} \mathrm{P}_{52}$ & 314 & 399 & 345 & 353 & 16 & 4,7 \\
\hline \multicolumn{5}{|c|}{ вразброс под предпосевную культивацию } \\
\hline $\mathrm{N}_{24} \mathrm{P}_{52}$ & 361 & 432 & 395 & 396 & 59 & 17,5 \\
\hline $\mathrm{N}_{48} \mathrm{P}_{52}$ & 389 & 435 & 427 & 417 & 80 & 23,7 \\
\hline $\mathrm{N}_{48} \mathrm{P}_{52} \mathrm{~K}_{48}$ & 347 & 444 & 380 & 390 & 53 & 15,7 \\
\hline $\mathrm{N}_{72} \mathrm{P}_{52}$ & 365 & 431 & 382 & 393 & 56 & 16,6 \\
\hline $\mathrm{N}_{72} \mathrm{P}_{52} \mathrm{~K}_{48}$ & 346 & 425 & 367 & 379 & 42 & 12,5 \\
\hline \multicolumn{5}{|c|}{ внесение минеральных удобрений и биопрепаратов при посеве } \\
\hline КЛ-10 & 312 & 420 & 356 & 363 & 26 & 7,7 \\
\hline $\mathrm{N}_{24} \mathrm{P}_{52}+$ КЛ-10 & 360 & 417 & 390 & 389 & 52 & 15,4 \\
\hline Мизорин & 313 & 399 & 364 & 359 & 22 & 6,5 \\
\hline $\mathrm{N}_{24} \mathrm{P}_{52}+$ Мизорин & 341 & 381 & 387 & 370 & 33 & 9,8 \\
\hline Флавобактерин & 371 & 411 & 412 & 398 & 61 & 18,1 \\
\hline $\mathrm{N}_{24} \mathrm{P}_{52}+$ Флавобактерин & 360 & 388 & 390 & 379 & 42 & 12,5 \\
\hline НСР & 33 & 31 & 26 & \multicolumn{3}{c|}{} \\
\hline
\end{tabular}

\section{Литература}

1. Андриюк А.В. Сафлор в Курганской области [Текст] / А.В. Андриюк // Аграрная наука, образование, производство: актуальные вопросы. Сборник трудов всероссийской научно-практической конференции с международным участием. 2014. С. 135 - 138.

2. Конопля, Н. Особенности выращивания сафлора и защита посевов от сорняков [Текст] / Н. Конопля, О. Курдюкова, Е. Жердева // Гл. Агроном. 2013. № 12. С. 32 - 33.

3. Зональные системы земледелия Ростовской области на 2013-2020 годы: монография. Ч. ІІ. [Текст] / Бондаренко С.Г., Горбаченко Ф.И., Горячев В.П., Гринько А.В., Егорова О.В., КаптулевС.И., Костылев П.И., Кравченко А.Н., ЛабынцевА.В., Пасько С.В., Пахомов В.И., Рыков В.Б., Фетюхин И.В., ЦелуйкоО.А., Шурупов В.Г. Ростов н/Д.: ООО "Донской издательский дом", 2013. Часть 2. 243 с. 